\title{
Teaching the Millennials: Implications on Today's Classrooms
}

\author{
Maizatul Akmal Mohd Mohzan*, Hanani Ahmad Zubir \\ Academy of Language Studies, Universiti Teknologi MARA (UiTM), Malaysia
}

Received July 9, 2019; Revised September 9, 2019; Accepted September 16, 2019

Copyright $@ 2019$ by authors, all rights reserved. Authors agree that this article remains permanently open access under the terms of the Creative Commons Attribution License 4.0 International License

\begin{abstract}
English teaching professionals dealing with students from all levels of education are reported to have faced challenges in meeting their students' needs. Born into the world of information, the Millennials are comprised of digital learners who are comfortable using technology in their everyday life. Students' predilection for technology is calling the educators to align their teaching strategies with students' learning preference. This paper therefore looks at the challenges educators face in teaching the Millennials as well as the strategies adopted in meeting the needs of this new generation. The survey which involved a department of language lecturers provides further insights into the discourse of teaching and learning in higher learning institutions.
\end{abstract}

Keywords Millennials, Net Generation, Digital Learners

\section{Introduction}

Teachers who work with children, adolescents and adults in all levels of education know that there is a difference in the way learners nowadays think and behave as compared to that of previous generations. The majority of these learners were born immersed in digital technology and are very comfortable using it in their daily activities, may it be for social or educational purposes. Volumes of research, as well as opinions from higher learning communities assert that educators need to respond to the needs of these digital learners.

The nature of the Millennials, or also known as Net generation who are tech-savvy and exhibits preference for the use of digital tools, has called for teachers to adapt to their students' multisensory learning styles. The traditional way of teaching such as chalk-and-talk, and the way in which teacher use printable handouts and is textbook-dependent are increasingly becoming more irrelevant to these learners. To some teachers, especially those of different generations and are relatively new to digital technologies, it might be a challenge to tailor teaching approaches to fulfil the needs of this net generation. Therefore, this survey seeks to examine teachers' understanding, strategies used and challenges involved in teaching these digital learners.

\section{Literature Review}

\subsection{Definition and Characteristics of Digital Learners}

Digital learners, also known as the Net generation or the Millennials, are students who have grown up surrounded by and immersed in digital technologies in their everyday life. The majority of these learners were born in early 1990s up to present and is also referred to as Gen Y and Gen Z (Lancaster and Stillman, 2002). These learners are known to be tech-savvy for their preference to use digital devices in doing their daily activities from socializing, learning and seeking entertainments. They respond quickly to fast and attractive visuals and sounds as a result of exposure to multimedia in this digital era.

This generation is also characterized by their predilection for entertainment and games. Growing up in a world that has always Internet, it is common for digital learners to spend hours in front of devices screens playing video games, watching movies and keeping updated on social media. In the US, Rideout, Foehr \& Roberts (2010) found out that four hours and a half per day was spent to use mobile phones and computers by adolescents aged between 8 and 18 years old to talk to peers, listen to music, watch videos, play games and access social media websites. Having access to digital devices and Internet almost all the time has also led digital learners to always opt for quick answers rather than longer problem-solving. This 
generation are used to getting instant information on almost anything from the Internet that they are inclined to look for shortcuts without seriously considering neither the reliability of the information they get nor the ethicality of their conduct.

Another trait of learners in this digital era that can pose a problem is that they have relatively shorter attention span compared to students from previous generations. With persistent exposure to multimedia content that consists of enticing visuals and engaging music, digital learners easily lose focus when presented with traditional text without interactive graphics. They are used to fast delivery of content, data, and images from digital screens that appeal to their preference for multisensory materials. Therefore this generation is often portrayed as demanding immediate gratification, with short attention spans and no tolerance for delays (Frand, 2000; Oblinger, 2003, Prensky, 2001a, 2001b) as cited in Smith (2012).

\subsection{Meeting the Needs of Digital Learners in Higher Learning Institutions}

In the last few decades, higher education communities have taken more interest and efforts in responding to the different needs of these digital learners. The demand for technology to be used in the educational setting is the reason why many higher learning institutions are going through transformational changes in doing their core business (Smith, 2012). These changes are necessary in order to accommodate to the "more technologically-driven, spontaneous and multi-sensory" learning preference (Prensky, 2001).

\subsubsection{Using Digital Multimedia to Aid In-class Lessons}

Incorporating technology in teaching can be done both in and outside of the classrooms. In classroom, digital learners benefit from digital content that teachers use to supplement traditional teaching materials, for example, the use of PowerPoint, Powtoon and Prezi to deliver lectures on top of the use of whiteboard and printouts. Other than that, having access to online videos and educational websites also helps students get access to authentic, interactive and interesting materials than can aid learning. Indeed, ICT has been used effectively in supporting traditional forms of teaching and administration in higher education institutions. Drawing data from the Speak Up 2014 survey conducted in US, Beerer (2016) reported that $40 \%$ of K-12 students watch online videos to help them understand concepts they learn in schools and a growing number of students are producing digital contents such as YouTube videos, slideshows and interactive games. The students are also reported to expect to use these digital resources to aid their learning.

\subsubsection{Incorporating Problem-Based Learning}

Using problem-based learning is one of the techniques proposed by many instructors in teaching digital learners. Problem-based Learning (PBL) is a teaching method in which complex real-world problems are used as the vehicle to promote students' learning of concepts and principles as opposed to direct presentation of facts and concepts. Beerer (2016) supports this when she emphasises that using relevant, problem-based teaching and learning serves digital learners as these learners naturally use their digital devices may it be smartphones or laptops to gather, organize and share information with classmates, teachers, parents and experts in finding solutions to real-life problems. A survey called Project Tomorrow involving 3.5 million students, faculty, parents and administrators carried out in 2003 found that digital learners are interested in things that are happening around the world. They frequently use digital tools and resources and become self-directed learners in learning and solving problems both in academic setting and in personal life (Humes, 2014).

\subsubsection{Promoting Blended Learning}

The term blended learning is generally applied to the practice of using both online and in-person learning experiences when teaching students. In blended learning, students learn in part through online learning and they have an element of control over where, when and how they want to work. Being active in self-directed learning, digital learners thrive in learning environments that is not only confined within the four walls of the classrooms. Blended learning provides this opportunity as students are required to go online to complete any tasks or assignments at a time that is convenient for them. Lai (2010) asserts that to meet the demands of the $21^{\text {st }}$ century learners with preference for digital technologies, learning should be extended beyond the physical classrooms as it provides learners with lifelong learning skills that encourage collaboration and networking, which is an aspect that is very much valued by digital learners.

\subsection{Barriers in Accommodating to Digital Learners}

Although there is a widespread acceptance among the higher learning communities on the need to respond to the digital learners' learning preference, the transformational changes are not without risks and problems. Rogers, Usher and Kaznowska (2011) as reported in Smith (2012) stated that overgeneralizing that all Net generations as digital learners who are comfortable and competent users of technologies can be damaging to the undergraduates as few researches have been carried out about the use of learning technologies from the perspectives of the so-called digital natives themselves. This is because not all Net generations have equal access and exposure to technologies. Other than that, Lai (2011) stated that many educators in higher learning institutions are reluctant to invest in 
technology-enhanced teaching as there is little value in terms of career advancement. This is due to universities policies that commonly value research outputs as compared to performance in teaching. Lack of ICT facilities by the universities due to high cost is also cited as one of the barriers to using educational technologies in higher learning.

\section{Methodology}

In collecting data for this survey, a self-report questionnaire was administered to 30 lecturers from a language department of a public university. The questionnaire consists of four sections. Section A requires participants to provide background information such as age, gender and years of teaching experience while section $\mathrm{B}$ attempts to identify the respondents' understanding of digital learners. Section $\mathrm{C}$ on the other hand examines the strategies teachers in use in teaching digital learners while Section D focuses on examining how the respondents perceive employing the strategies as challenging. Respondents were required to respond to the items which employ a 7-point Likert scale.

\section{Findings and Discussion}

\subsection{Examining Teachers' Understanding of Digital Learners}

Based on the survey responses it was found that the majority of the respondents (86.7\%) strongly agree that digital learners prefer to use digital tools in learning. All 30 respondents agree that digital learners respond to loud and quick visuals, audio, and music and that these learners show preference for entertainment and games. Slightly more than three-quarter $(76.7 \%)$ agree that digital learners tend to opt for quick answers rather than longer problem-solving and only 1 respondent disagree to the statement. Despite almost all (96.7\%) agreed that digital learners are self-focused and highly confident learners, 93.4\% of the respondents felt that digital learners possess shorter attention span.

As a whole, it can be seen that a vast majority of the respondents agree that their students possess the characteristics of digital learners as have been discussed in much literature. Although it has been cautioned by Rogers, Usher and Kaznowska (2011) that not all Net generation are digital natives, it seems that to most of these respondents, their leaners fit the profile of digital learners.

\section{Teachers' Understanding of Digital Learners}

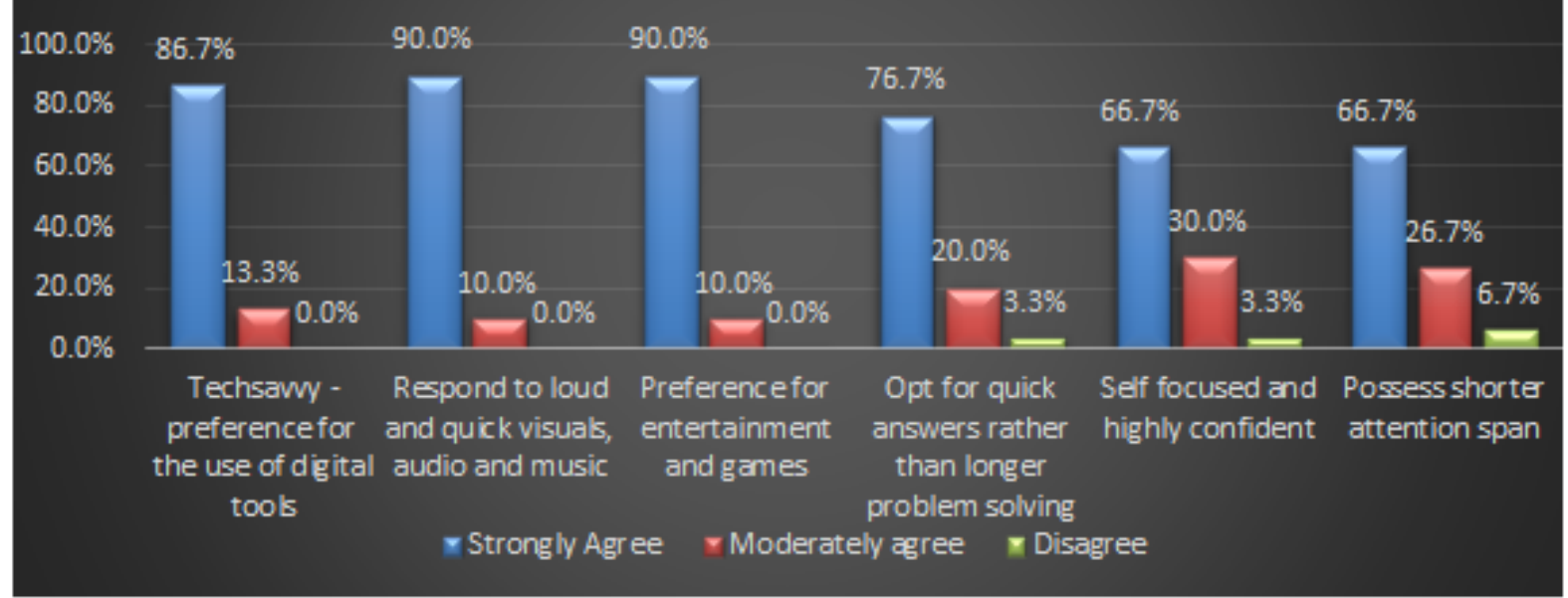

Figure 1. Teachers' Understanding of Digital Learners 


\subsection{Identifying Strategies Adopted in Teaching Digital Learners}

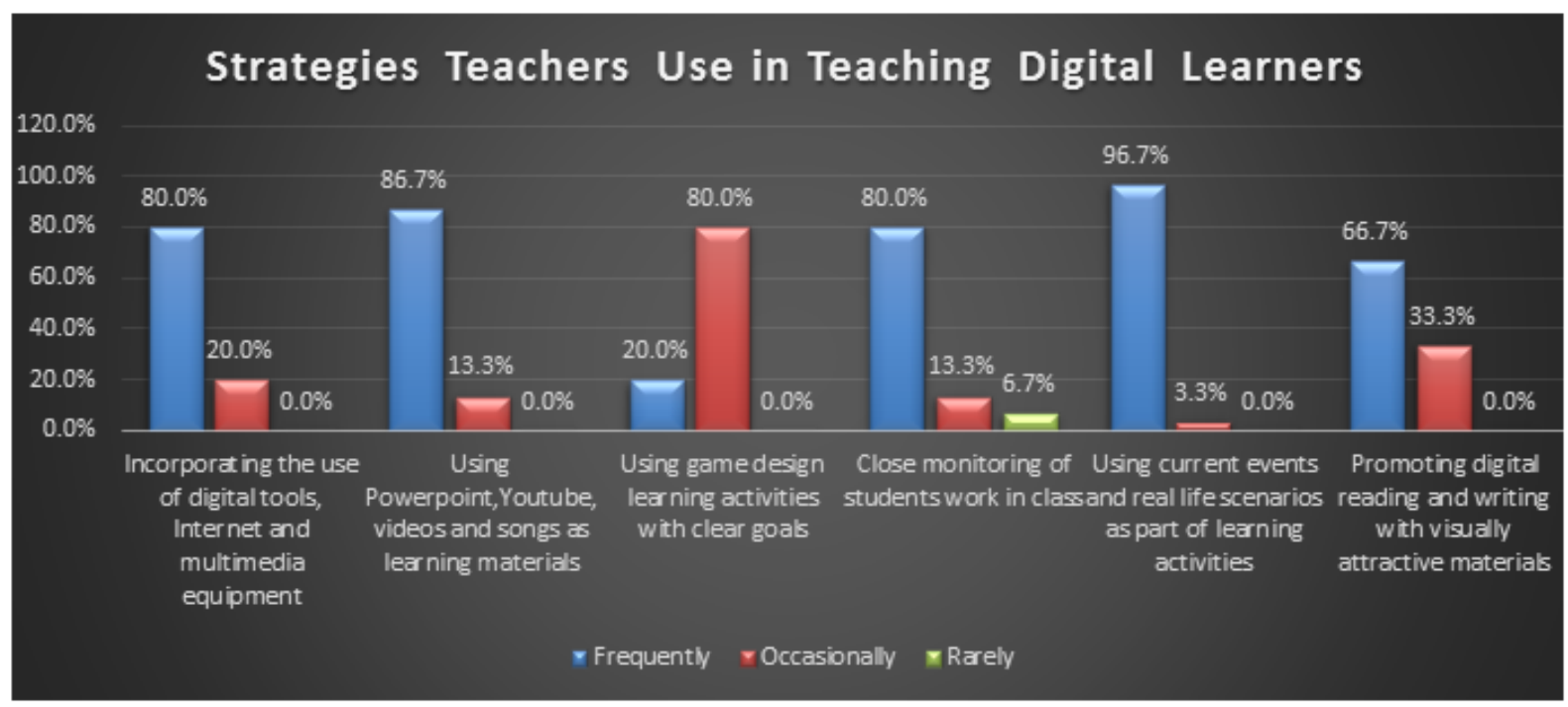

Figure 2. Strategies Teachers Use in Teaching Digital Learners

The majority of the respondents (80\%) are reported to be frequent users of digital tools, Internet and multimedia equipment in teaching their students whereas the remaining $20 \%$ claimed to be only occasional users. Almost similar figures (86.7\%) reported the frequently using of Powerpoint, Youtube, videos and songs as learning materials and $13.3 \%$ claimed to use it occasionally. Less than a quarter $(20 \%)$ of the respondents reported to be frequent users of game design learning activities with clear learning goals in teaching the digital learners and the majority ( $80 \%$ ) claimed to do this occasionally. $80 \%$ of the respondents are also reported to frequently monitor their students' work in class as to avoid academic dishonesty. Almost all respondents (96.7\%) claimed that they frequently used current events and real-life scenarios as part of learning activities and almost two-thirds (66.7\%) frequently promoted digital reading and writing with attractive graphics to engage their digital learners.

The findings of the survey indicate that the majority of the respondents attempted to tailor to the needs of the digital learners by incorporating the use of multimedia in their teaching. Additionally, recognizing that the Net generation are self-focused learners, the respondents frequently took the effort to use real life scenarios that learners can personally relate to as to better engage them in learning. In September 2015 contribution to the eLearning
Industry website, Timothy advocates for the learner-centred approach by outlining seven advantages: improves participation, improves retention of knowledge, boosts performance at work, develops problem-solving skills, fosters collaborative learning, makes learning more enjoyable as well as facilitates personalized learning. The respondents' occasional use of game design learning activities also contributes to the learning style of digital learners who have largely grown up exposed to video games. Drawing data from the Summit on Educational Games, The Federation of American Scientists (2006) has illustrated the benefits of learning that incorporates game attributes such as providing clearly defined goals, ample practice opportunities, continuous feedback, scaffolding as well as personalization. The majority of the respondents are also reported to have frequently monitored their students' work in the effort to deter academic dishonesty. Combes (2005) claimed that academic dishonesty is prominent among the Net generation due to the changing culture of information that is easily accessed, manipulated and disseminated to global audience. In the effort to combat plagiarism effectively in education, she proposed a few strategies that can be used by teachers including using plagiarism-detection website and software as well as producing authentic assessments that require higher order thinking skills. 


\subsection{Identifying Challenges Teachers Face in Teaching Digital Learners}

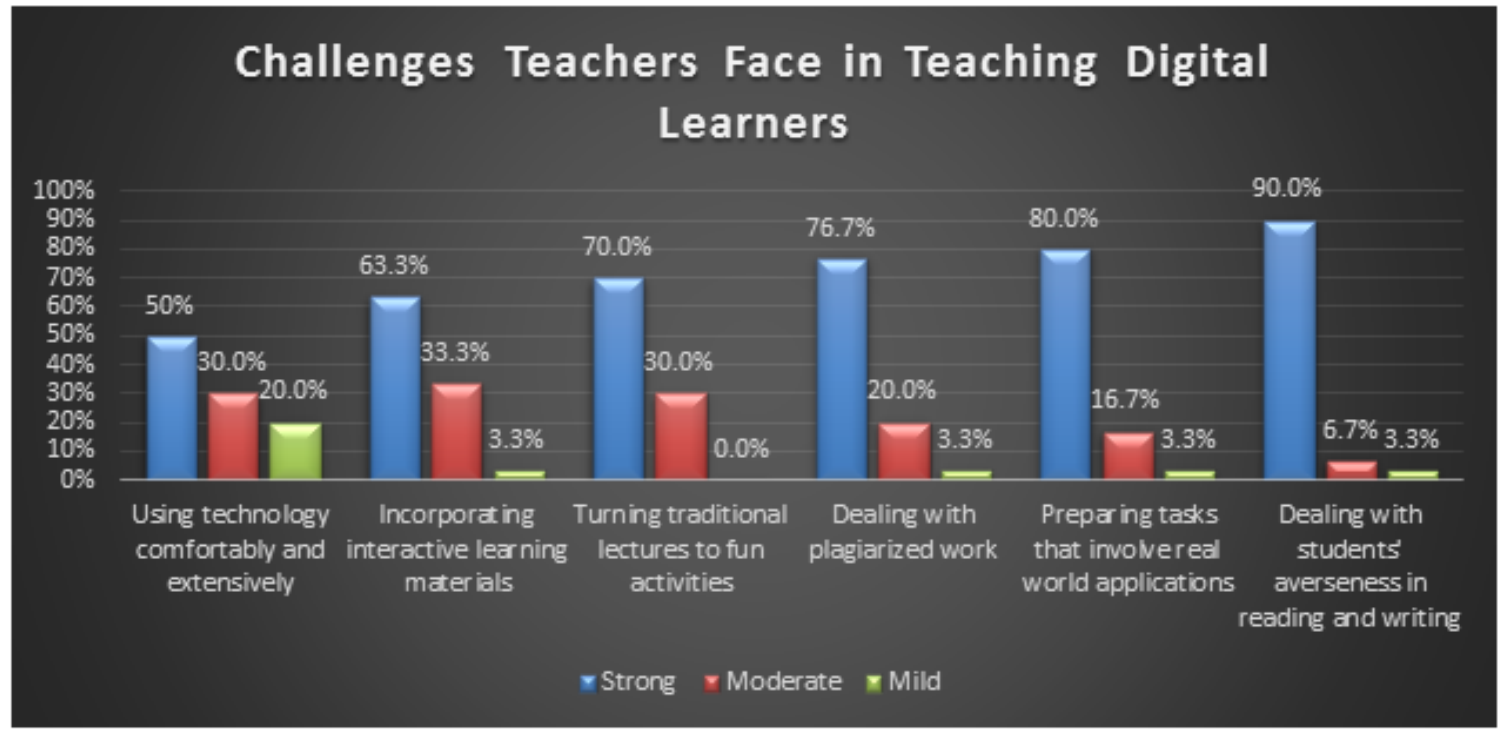

Figure 3. Challenges Teachers Face in Teaching Digital Learners

In examining the challenges teachers face in teaching digital learners, it was found that more than half to almost all respondents (50\%-90\%) felt that it posed a strong challenge for them in using technology comfortably and extensively in teaching, incorporating interactive learning materials into lessons, dealing with plagiarized work among students, preparing tasks that involve real world applications as well as dealing with students' averseness in reading and writing class. The remaining of the respondents, which is less than one-third (33.3\% and below) of the respondents, felt that all these efforts posed only a moderate challenge for them in teaching these digital learners.

In general, the finding shows that although the respondents did try to tailor to their digital learners' needs, they perceived the efforts as challenging. It can be concluded that the biggest challenge in catering to this generation is dealing with the students' averseness in reading and writing, followed by preparing tasks that involve real life applications, dealing with plagiarized work, turning traditional lecturers to fun activities, incorporating interactive learning materials and using technology comfortably and extensively. There may be a few reasons as to why teachers find it a challenge to incorporate technology into their classrooms. Some of the reasons may be due to cost and time constraint. Apart from that, teachers who are of older generations and less active users of digital devices and Internet (digital immigrants as Prensky (2001) puts it) might be apprehensive in using technology in classrooms as it requires efforts to keep up with the continuous technological demands in teaching the Millennials.

\section{Conclusions}

This survey supports the claim that current students in higher learning institutions consist of Net generation the majority of whom possess the characteristics of digital learners. Digital learners are known to thrive in learning environment that incorporates the use of technology in teaching and learning. Because of technology as well, there are some challenges that teachers have to face in teaching this generation such as their tendency to commit academic dishonesty and reduced interest in reading. Therefore, it is crucial for educators to be mindful of these learners' characteristics and tendency to enable them to adopt teaching strategies that fulfil the academic needs of these students. The strategies largely involve embedding digital technologies both in class and beyond classroom learning which calls for teachers' readiness to change from traditional teaching to more learner-focused. As Laurillard (2008) puts it, incorporating digital technologies in education helps to produce learning that is not only active but also participatory, personalized, flexible as well as inclusive.

\section{Acknowledgement}

The authors would like to gratefully acknowledge Universiti Teknologi MARA (UiTM) Cawangan Pulau Pinang for the financial support for our participation at this conference. 


\section{REFERENCES}

[1] Beerer, K. (2016). 4 go-to strategies for engaging digital learners for instructional leaders and teachers: Discovery education. Retrieved from http://blog.discoveryeducation.c om/blog/2016/02/16/4-go-to-strategies-for-engaging-digita l-learners/

[2] Combes, B. (2005). The copy-and-paste culture of the Net Generation: Strategies for dealing with plagiarism. ECU Publications.

[3] Federation of American Scientists (2006). Summit on educational games: Harnessing the power of video games for learning. Washington, DC: https://fas.org/programs/ltp/policy_and_publications/summ it/Summit\%20on\%20Educational\%20Games.pdf

[4] Humes, L. R. (2014). The Challenge of Educating Today's Digital Natives. IMS Global Learning Consortium Series on Learning Impact. Retrieved from http://www.imsglobal.org/articles/SLI11-032014.pdf

[5] Lai, K. W. (2011). Digital technology and the culture of teaching and learning in higher education. Australasian Journal of Educational Technology, 27(8), 1263-1275.

[6] Lancaster, L. C., and D. Stillman. 2002. When generations collide: Who they are, why they clash, how to solve the generational puzzle at work. New York: HarperCollins.

[7] Laurillard, D. (2008). Digital technologies and their role in achieving our ambitions for education. London: Institute of Education, University of London. http://eprints.ioe.ac.uk/628/1/Laurillard2008Digital_techno logies.pdf

[8] Prensky, M. (2001a). Digital natives, digital immigrants (Part 1). On the Horizon, 9(5), 1-6.

[9] Rideout, V., Foehr, U., \& Roberts, D. (2010). Generation M2: Media in the lives of 8- to 18-year-olds. A Kaiser Family Foundation Study. http://www.kff.org/entmedia/mh012010pkg.cfm

[10] Rogers, J., Usher, A. \& Kaznowska, E. (2011). The state of e-learning in Canadian universities, 2011: If students are digital natives, why don't they like e-learning? Higher Education Strategy Associates. Retrieved from http://higheredstrategy.com/wpcontent/Uploads/2011/09/in sightbrief42.pdf

[11] Smith, E. (2012). The digital native debate in higher education: A comparative analysis of recent literature. Canadian Journal of Learning and Technology, 38(3). http://dx.doi.org/10.21432/T2F302

[12] Timothy, A. (2015). Learner centred approach: Does it really matter in eLearning?: eLearning industry. Retrieved from https://elearningindustry.com/learner-centered-approach-el earning 